\title{
Correction to: The fate of root canals obturated with Thermafil: 10-year data for patients treated in a master's program
}

\author{
Chiara Pirani $^{1} \cdot$ Fausto Zamparini ${ }^{1} \cdot$ Ove A. Peters $^{2}$ • Francesco lacono ${ }^{1} \cdot$ Maria Rosaria Gatto ${ }^{1}$. Luigi Generali ${ }^{3}$. \\ Maria Giovanna Gandolfi ${ }^{1}$. Carlo Prati ${ }^{1}$
}

Published online: 1 April 2019

(C) Springer-Verlag GmbH Germany, part of Springer Nature 2019

\section{Correction to: Clinical Oral Investigations https://doi.org/10.1007/s00784-018-2756-8}

The author names in the original version of this article were inadvertently interchange. Correct presentation of author names is reflected here.

The original article has been corrected.

Publisher's note Springer Nature remains neutral with regard to jurisdictional claims in published maps and institutional affiliations.

The online version of the original article can be found at https://doi.org/ 10.1007/s00784-018-2756-8

\section{Chiara Pirani}

chiara.pirani4@unibo.it

1 Endodontic Clinical Section, School of Dentistry, Department of Biomedical and Neuromotor Sciences (DIBINEM), Alma Mater Studiorum University of Bologna, Via San Vitale 59, 40125 Bologna, Italy

2 Arthur A. Dugoni School of Dentistry, University of the Pacific, San Francisco, CA, USA

3 Department of Surgery, Medicine, Dentistry and Morphological Sciences with Transplant Surgery, Oncology and Regenerative Medicine Relevance, School of Dentistry, Endodontic Section, University of Modena and Reggio Emilia, Modena, Italy 